\title{
Seroprevalence of Toxoplasma gondii and Neospora caninum in goats from north-western Spain
}

\author{
Pablo Díaz', Eva Cabanelas', José Manuel Díaz', Miguel Viña', Juan Pablo Béjar', Ana Pérez-Creo', \\ Alberto Prieto', Ceferino Manuel López', Rosario Panadero', Gonzalo Fernández', \\ Pablo Díez-Baños' ${ }^{1}$, Patrocinio Morrondo' \\ ${ }^{1}$ Animal Pathology Department (INVESAGA Group), Faculty of Veterinary Medicine. Universidade de Santiago de Compostela. \\ Campus Universitario $s / n$, Lugo, Spain
}

Díaz P, Cabanelas E, Díaz JM, Viña M, Béjar JP, Pérez-Creo A, Prieto A, López CM, Panadero R, Fernández G, Díez-Baños P, Morrondo P. Seroprevalence of Toxoplasma gondii and Neospora caninum in goats from north-western Spain. Ann Agric Environ Med. 2016 ; 23(4): 587-590. doi: $10.5604 / 12321966.1226851$

\begin{abstract}
Introduction and objective. Toxoplasma gondii and Neospora caninum are protozoans involved in reproductive failure especially in ruminant livestock. The objective was to estimate the seroprevalence of both parasites in goats from northwestern Spain and to study the influence of some factors on seropositivity.

Materials and method. Blood samples from 638 goats were collected in 50 farms. Presence of T. gondii and N. caninum antibodies were detected by direct agglutination and competitiveELISA techniques, respectively. The risk factor analysis was performed using a mixed-effects logistic regression.

Results. Individual (48\%) and herd-level (74\%) T. gondii seroprevalence values were high; the within-herd prevalence was $53 \%$. In contrast, $6 \%$ of animals tested positive to $N$. caninum and $38 \%$ of the herds had at least one positive animal, with a true within-herd prevalence of $10 \%$. Mixed infections were limited; $91 \%$ of $N$. caninum seropositive goats were also positive to $T$. gondii. The risk factor analysis showed that $T$. gondii seroprevalence is influenced by the presence of sheep in the farm $(\mathrm{OR}=4.9)$ and the seropositivity to $N$. caninum ( $\mathrm{OR}=16.5)$; goats from the Central-coastal area, more humid and warm, had a 15.7-fold probability of being seropositive to T. gondii than those from the Mountainous area. Cross-breed goats (OR=4.5) and the seropositivity to $T$. gondii $(\mathrm{OR}=9.5)$ were factors associated with $N$. caninum seropositivity.

Conclusions. The high T. gondii seroprevalence in goats constitute a noticeable zoonotic risk. The consideration of the risk factors identified in designing T. gondii and N. caninum control programs in goat herds should allow the implementation of more efficient measures, avoiding the appearance of outbreaks of reproductive disorders by both protozoans in goats.
\end{abstract}

Key words

Toxoplasma gondii, Neospora caninum, goat, Spain, risk factors

\section{INTRODUCTION}

Toxoplasma gondii and Neospora caninum are worldwidedistributed apicomplexan parasites strongly associated with reproductive problems in ruminants, such as foetal reabsorption, abortions, foetal mummification, still birth and neonatal losses, leading to substantial economic losses in livestock production $[1,2]$.

Toxoplasmosis is considered one of the major causes of infectious reproductive failure in ovine and caprine livestock [3]. The zoonotic role of $T$. gondii has been demonstrated since the consumption of infected raw/undercooked meat or milk causes human infection [4]. N. caninum is responsible for reproductive failure in several animal species; studies on N. caninum infections in caprine livestock are limited when compared to other ruminant species, especially cattle $[3,5]$. Although several investigations have isolated $N$. caninum and described Neospora-associated lesions from aborted goat foetuses $[6,7,8]$, the real epidemiological importance of neosporosis in this small ruminant have not been completely elucidated.

Address for correspondence: Pablo Díaz, Facultad de Veterinaria. Pabellón I, Planta Baja, Campus Universitario s/n, 27002, Lugo, Spain

E-mail: pablo.diaz@usc.es

Received: 19 April 2016; accepted: 16 June 2016
Studies carried out in north-western Spain have revealed noteworthy seroprevalence rates of $T$. gondii and $N$. caninum in sheep (38-58\%; 6-10\%) and cattle (7\%; 16\%-24\%) [9, 10, 11, $12]$, but no data are available on goats. This epidemiological information could be useful for studying outbreaks of reproductive disorders on goat farms, since animals could be exposed to T. gondii or N. caninum without apparent reproductive problems; consequently, performing serological studies after abortion outbreaks could lead to erroneous conclusions if the analysis does not consider the population seroprevalence [9].

The aim of this study was to estimate the seroprevalence and risk factors for T. gondii and N. caninum in goats from north-western Spain. This information would be of great interest for implementing new preventive strategies against these protozoans in goats.

\section{MATERIALS AND METHOD}

Study area and goat population. Galicia (north-western Spain) is a major Spanish livestock production area where the goat sector is poorly developed and professionalized and represents a small percentage of the Galician livestock sector; in 2012 , the goat population was only 44,624 animals [13]. 
Goats are mainly managed under a traditional husbandry system and commonly reared mixed with sheep. The highest goat census and largest herds are located in mountainous areas, owing to goat rusticity and adaptability to unfavourable environments where pastures are scarce and other species may not be economically productive. The autochthonous 'Cabra Galega' breed is especially adapted to such zones and is present throughout the entire study area.

In north-western Spain, goats are mainly reared using two different management systems, they generally graze near the farm during the day and are brought indoors at night in the semi-extensive system, and during mild seasons go to large grazing areas, passing long periods outdoors in the extensive season.

According to geographic and climatic conditions, two different areas were previously considered in the study area [14]: a central-coastal area with moderate rainfall $(<1,500 \mathrm{~mm} /$ year $)$ and warm temperature $\left(\bar{x}=12.3^{\circ} \mathrm{C}\right)$ and a mountainous area with lower temperatures $\left(\bar{x}=10.1^{\circ} \mathrm{C}\right)$ and higher precipitation (>1,500 $\mathrm{mm} /$ year $)$.

Serological study. Sample size was calculated for a confidence interval of $99 \%$ and $95 \%$ precision, establishing an estimated seroprevalence of $58 \%$ according to previous reports in sheep from the same study area $[9,12]$. Thus, 638 goat blood samples were randomly taken from 50 farms between 2010-2013. Samples were taken by jugular puncture and sera stored at $-20^{\circ} \mathrm{C}$ until analysed.

Toxoplasma-specific IgG antibodies were detected by a direct agglutination commercial kit (Toxo-Screen DA, BioMérieux, Lyon, France) using the manufacturer's instructions. All samples were also analysed for the presence of $N$. caninum antibodies using a commercial competitive ELISA (cELISAVMRD, VMRD, Pullman, USA). According to the product leaflet, serum samples were considered positive when the inhibition percentage was greater than $30 \%$. Sensitivity and specificity values provided by the manufacturer were used to calculate the true seroprevalence [15]. Farms were considered positive when their true seroprevalence was $>0$.

Risk factors considered and statistical analysis. In order to investigate the possible influence of some factors on T. gondii and $N$. caninum seroprevalence values, farmers were asked to complete a herd management questionnaire on the day of sampling. Gender, breed and date of birth of animals were obtained from official individual registers. Variables and their categorization are summarized in Table 1.

Herd size categories were chosen in order to obtain similar number of cases in each herd; the number included goats and sheep present on the farm. The influence of $N$. caninum seropositivity on the presence of T. gondii antibodies and vice versa was also studied. Although it has been demonstrated that the presence of cats and dogs in the farm represent a risk factor to acquire T. gondii and N. caninum infections, respectively, these variables were not considered in the present study as both species of domestic animals were present on all studied farms.

Seropositivity was analyzed with a Mixed-effects Logistic Regression algorithm. The dependent variable was the seropositivity to T. gondii or N. caninum at the individual level. Herd was introduced as a random factor to control its effect over factors. The variables defined previously were introduced in a backward conditional method and removed
Table 1. T. gondii and N. caninum seropositivity values in goats from north-western Spain considering the different variables included in risk factor analysis

\begin{tabular}{|c|c|c|c|}
\hline Variables & & $\begin{array}{c}\text { T. gondii } \\
\text { positive/total (\%) }\end{array}$ & $\begin{array}{c}\text { N. caninum } \\
\text { positive/total (\%) }\end{array}$ \\
\hline \multirow{2}{*}{ Age } & $\leq 12$ months & $31 / 64$ (48\%) & $2 / 64(3 \%)$ \\
\hline & $>12$ months & $268 / 574(47 \%)$ & 43/574 (8\%) \\
\hline \multirow{2}{*}{ Sex } & Female & 280/599 (47\%) & 43/599 (7\%) \\
\hline & Male & 19/39 (49\%) & $2 / 39(5 \%)$ \\
\hline \multirow{2}{*}{ Climatic area } & Central-coastal & 279/492 (57\%) & 38/492 (8\%) \\
\hline & Mountain & 20/146 (14\%) & $7 / 146(5 \%)$ \\
\hline \multirow[b]{2}{*}{ Breed } & Cross-breed & $256 / 460(56 \%)$ & $42 / 460(9 \%)$ \\
\hline & $\begin{array}{l}\text { "Cabra Galega" } \\
\text { Pure breed }\end{array}$ & $43 / 178$ (24\%) & $3 / 178(2 \%)$ \\
\hline \multirow{2}{*}{ Husbandry system } & Semi-extensive & $285 / 574(50 \%)$ & 42/574 (7\%) \\
\hline & Extensive & $14 / 64(22 \%)$ & $3 / 64(5 \%)$ \\
\hline \multirow{2}{*}{$\begin{array}{l}\text { Sheep } \\
\text { presence }\end{array}$} & At least one sheep & $241 / 455$ (53\%) & 40/455 (9\%) \\
\hline & Purely goat flock & $58 / 183(32 \%)$ & $5 / 183(3 \%)$ \\
\hline \multirow{3}{*}{ Flock size } & $<96$ animals & $72 / 208(35 \%)$ & 9/208 (4\%) \\
\hline & 96-194 animals & $110 / 169(65 \%)$ & $22 / 169(13 \%)$ \\
\hline & $>194$ animals & $117 / 261(45 \%)$ & $14 / 261(5 \%)$ \\
\hline \multirow[t]{2}{*}{ Seropositivity } & to N. caninum & $41 / 299$ (14\%) & - \\
\hline & to T. gondii & - & $41 / 45(91 \%)$ \\
\hline TOTAL & & 299/638 (48\%) & $45 / 638(6 \%)$ \\
\hline
\end{tabular}

from the model one by one on the basis of the AIC value until the best model was built. Next, all pairwise interactions that were biologically plausible were evaluated. These statistical analyses were performed with glmer() function from lme4 package in the $\mathrm{R}$ statistical programme ( $\mathrm{R}$ v.3.1.1; R Development Core Team, 2014).

\section{RESULTS}

Individual and flock seroprevalence of both parasites. The individual true seroprevalence to T. gondii was high (48\%), as well as the herd-level $(37 / 50 ; 74 \%)$ and the true withinherd $(53 \%)$ prevalence values. In contrast, a low percentage of animals tested positive to N. caninum (6\%) and 19/50 of the herds (38\%) had at least one positive animal, with a true within-herd prevalence of $10 \%$. At the individual-level, mixed infections were not common, since only $41 / 638$ of the examined goats (6\%) were seropositive to both $T$. gondii and $N$. caninum. Interestingly, all N. caninum positive herds were also positive to T. gondii.

Risk factors. Seroprevalence for each factor considered in the study are summarized in Table 1 . Cross-breed goats and those from coastal-central areas and medium-size herds presented the highest seroprevalence values for both protozoans. It was also observed that $N$. caninum and T. gondii seroprevalence was higher in animals reared together with sheep, and in a semi-extensive management system than the other; on the contrary, similar seropositivity percentages were observed in relation to gender. In contrast to that observed for T. gondii, an age-related increase in the $N$. caninum seroprevalence was recorded. 
Table 2. Results of Mixed-effects Logistic Regression (backward conditional method) of risk factors associated with individual T. gondi and $N$. caninum seropositivity in goats from north-western Spain

\begin{tabular}{lllc}
\hline & Estimate & Std. Error & P \\
\hline $\boldsymbol{T}$. gondii (step 6) & & & \\
\hline (Intercept) & 0.626 & 0.385 & 0.010 \\
\hline Seropositivity to Neospora & 2.802 & 0.683 & $<0.001$ \\
\hline Zone & -2.752 & 0.639 & $<0.001$ \\
\hline Sheep presence & -1.604 & 0.596 & $<0.001$ \\
\hline N. caninum (step 7) & & & \\
\hline (Intercept) & -4.080 & 0.583 & $<0.001$ \\
\hline Seropositivity to Toxoplasma & 2.249 & 0.610 & $<0.001$ \\
\hline Breed & -1.504 & 0.666 & 0.024 \\
\hline
\end{tabular}

Mixed-effects logistic regression results (Tab. 2) indicated that $T$. gondii seroprevalence in goats is mainly influenced by the climatic area, the presence of sheep on the farm and seropositivity to N. caninum. Thus, goats from the Centralcoastal area had a 15.7 -fold probability (95\% CI 4.5-54.9) of being seropositive than those from the mountainous area. In addition, the risk of being seropositive was 4.9 times higher (95\% CI 1.5-16.0) in those goat herds including sheep and 16.5 times higher (95\% CI 4.3-62.8) in those animals tested positive for N. caninum.

For N. caninum, the multivariate analysis results indicated that the breed and the seropositivity to $T$. gondii were factors associated with goat seropositivity. In this case, the probability of being seropositive was 4.5 -fold higher (95\% CI 1.2-16.6) in cross-breed goats and 9.5-fold higher $(95 \%$ CI 2.9-31.3) in those positive to T. gondii.

\section{DISCUSSION}

The presented study is the first population study on the seroprevalence of T. gondii and $N$. caninum in caprine livestock from northern Spain. The results obtained reveal a broad dissemination of both protozoans amongst goat farms and coincide with previous reports performed in sheep and cattle from the same area $[9,10,11,12]$. This suggests that climatic and management factors facilitate the survival of oocysts in the environment and the contact between definitive and intermediate hosts. The high seroprevalence values of T. gondii found in this present study also implies a real risk for public health [4].The higher individual prevalence observed for T. gondii than for N. caninum in Galician caprine livestock is in agreement with several European serological studies in goats where both protozoans were investigated $[16,17,18$, 19]. These studies show T. gondii individual seroprevalences greater than 53\%, whereas $N$. caninum values do not exceed $16 \%$. In this way, the within-herd seroprevalence is considerably lower in N. caninum than in T. gondii, despite the percentage of positive herds being moderately high.

A limited number of animals showed mixed infections, but 91.1\% of N. caninum seropositive goats were also positive to T. gondii. Similarly, Bartova and Sedlak [16], using the same cELISA for detecting anti-N. caninum antibodies, observed that all goats testing positive to $N$. caninum were also positive to T. gondii. In addition, González-Warleta et al. [11] found that dairy cattle infected with T. gondii showed a higher seroprevalence by N. caninum. In this regard, Álvarez-García et al. [20] found a low specificity (65.1-66.5\%) for the VMRD cELISA using the manufacturer's cut-off value, suggesting that cross-reactions with other closely-related protozoans, such as Sarcocystis spp., may be responsible for these false positive results. This may be the reason for identification of $T$. gondii seropositivity as a risk factor for N. caninum seropositivity and vice versa. In contrast, Čobádiová et al. [17] observed a better specificity of the cELISA-VMRD using the manufacturer's cut-off value.

Mixed-logistic regression results showed that goats from central-coastal areas presented a significantly higher probability of being seropositive to $T$. gondii than those from the mountain area, as reported in sheep from the same region $[9,12]$. The constant level of humidity and the higher mean annual temperature of the central-coastal area favour the sporulation, viability and spread in the environment of T. gondii oocysts [21]. In addition, goats from the mountain area usually spend long periods in large low-density grazing areas, away from both residential areas and goat facilities, where contact with the definitive host, and therefore the risk of infection, is less common [22].

Goats reared with sheep showed higher seroprevalence of $T$. gondii than those belonging to pure flocks. Those results are consistent with the findings of Gazzonis et al. [23], who observed an infection risk 1.39 times higher in goats from mixed farms. In mixed farms, a higher T. gondii seroprevalence has been found in sheep than in goats, which may be due to their foraging behaviour and diet selection [24]; while goats tend to eat from higher bushes and shrubs, sheep tend to graze close to the soil, being more likely to ingest oocysts on the pasture. All those data suggest that sheep act as an indirect facilitator of $T$. gondii exposure to caprine livestock. Further research to unravel the relationships between these two ruminant species in the epidemiology of T. gondii is needed to improve understanding of the behavior of toxoplasmosis on mixed farms.

The 'Cabra galega' autochthonous pure breed showed a significantly lower seroprevalence to N. caninum (1.7\%) than cross-breed goats (9.1\%). Although previous investigations are not very conclusive concerning the role of breed on infection by $N$. caninum, some authors have reported lower prevalence values in rustic and local breed goats than in cross-breeds [25]. In this sense, Pérez-Creo et al. [26] reported that the 'Cabra Galega' breed also showed significantly lower seroprevalence values for Fasciola hepatica than cross-breed animals.

\section{CONCLUSIONS}

The presented results reveal that the seroprevalence values of T. gondii are very high in caprine livestock from northwestern Spain, thus representing a noticeable zoonotic risk. The data obtained show that the rearing of goats, while avoiding the presence of sheep in the herd, is a useful practice for reducing the seroprevalence of T. gondii and, consequently, the risks to other hosts. The use of locally adapted breeds may also be important for reducing the presence of $N$. caninum in goat populations, although further studies are needed to elucide the real role of caprine livestock on the epidemiology of this protozoan. Consideration of the risk factors identified in this study should allow the application of more efficient measures when designing T. gondii and N. caninum control 
programmes, avoiding the appearance of outbreaks of reproductive disorders by both protozoans in goats.

\section{Acknowledgements}

The authors express their thank to OVICA (Galician Association of Ovine and Caprine Breeders), BOAGA (Galician Autochthonous Breed Federation) and the veterinarians of the ADSG ACIVO for their collaboration in this study. This work was supported by a Programme for consolidating and structuring competitive research groups (GRC2015/003, Xunta de Galicia) and by the Research Project 'RUMIGAL: Rede de estudomultidisciplinar dos ruminantesen Galicia’ (R2014/005, REDES, Xunta de Galicia).

\section{REFERENCES}

1. Freyre A, Bonino J, Falcón J, Castells D, Correa O, Casaretto A. The incidence and economic significance of ovine toxoplasmosis in Uruguay. Vet Parasitol. 1999; 81: 85-88.

2. Reichel M P, Ayanegui-Alcérreca M A, Gondim L F, Ellis J T. What is the global economic impact of Neospora caninum in cattle - the billion dollar question. Int J Parasitol. 2013; 43: 133-142.

3. Dubey J P, Schares G. Neosporosis in animals - The last five years. Vet Parasitol. 2011; 180: 90-108.

4. Tenter A M, Heckeroth A R, Weiss L M. Toxoplasma gondii: from animals to humans. Int J Parasitol. 2000; 30: 1217-1258.

5. Abo-Shehada M N, Abu-Halaweh M M. Flock-level seroprevalence of, and risk factors for Neospora caninum among sheep and goats in northern Jordan. Prev Vet Med. 2010; 93: 25-32.

6. Barr B C, Anderson M L, Woods L W, Dubey J P, Conrad P A. Neosporalike protozoal infections associated with abortions in goats. J Vet Diagn Invest. 1992; 4: 365-367.

7. Eleni C, Crotti S, Manuali E, Costarelli S, Filippini G, Moscati L, et al. Detection of Neospora caninum in an aborted goat foetus. Vet Parasitol. 2004; 123: 271-274.

8. Moreno B, Collantes-Fernandez E, Villa A, Navarro A, Regidor-Cerrillo J, Ortega-Mora L M. Occurrence of Neospora caninum and Toxoplasma gondii infections in ovine and caprine abortions. Vet Parasitol. 2012; 187: 312-318.

9. Díaz J M, Fernández G, Prieto A, Valverde S, Lago N, Díaz P, et al. Epidemiology of reproductive pathogens in semi-intensive lambproducing flocks in North-West Spain: A comparative serological study. Vet J. 2014; 200: 335-338.

10. Eiras C, Arnaiz I, Alvarez-García G, Ortega-Mora L M, Sanjuán M L, Yus E, et al. Neospora caninum seroprevalence in dairy and beef cattle from the northwest region of Spain, Galicia. Prev Vet Med. 2011; 98: $128-132$.
11. González-Warleta M, Castro-Hermida J A, Carro-Corral C, CortizoMella J, Mezo M. Epidemiology of neosporosis in dairy cattle in Galicia (NW Spain). Parasitol Res. 2008; 102: 243-249.

12. Panadero R, Painceira A, López C, Vázquez L, Paz A, Díaz P, et al. Seroprevalence of Toxoplasma gondii and Neospora caninum in wild and domestic ruminants sharing pastures in Galicia (Northwest Spain). Res Vet Sci. 2012; 88: 111-115.

13. MAGRAMA. Anuario de Estadística Agraria, años 2011-2012; 2013 [cited 2016 Apr 19].Available from: http://www.magrama.gob.es/ estadistica/pags/anuario/2012/AE_2012_14_01_05_02.pdf.

14. Lago N, López C, Panadero R, Cienfuegos S, Pato J, Prieto A, et al. Seroprevalence and risk factors associated with Visna/Maedi virus in semi-intensive lamb-producing flocks in north western Spain. Prev Vet Med. 2012; 103: 163-169.

15. Noordhuizen J P T M, Frankena K, van der Hoofd C M, Graat E A M. Application of Quantitative Methods in Veterinary Epidemiology. Wageningen Academic Publishers; 1997.

16. Bartova E, Sedlak K. Toxoplasma gondii and Neospora caninum antibodies in goats in the Czech Republic. Vet Med-Czech. 2012;5 7: 111-114.

17. Čobádiová A, Reiterová K, Derdáková M, Špilovská S, Turčeková L, Hviščová I, et al. Toxoplasma gondii, Neospora caninum and ticktransmitted bacterium Anaplasmaphagocytophilum infections in one selected goat farm in Slovakia. Acta Parasitol. 2013; 58: 541-546.

18. Diakoua A, Papadopoulos E, Panousis N, Karatzias C, Giadinis N. Toxoplasma gondii and Neospora caninum seroprevalence in dairy sheep and goats mixed stock farming. Vet Parasitol. 2013; 198: 387-390.

19. Iovu A, Gyorke A, Mircean V, Gavrea R, Cozma V. Seroprevalence of Toxoplasma gondii and Neospora caninum in dairy goats from Romania. Vet Parasitol. 2012; 186: 470-474.

20. Álvarez-García G, García-Culebras A, Gutiérrez-Expósito D, NavarroLozano V, Pastor-Fernández I, Ortega-Mora LM. Serological diagnosis of bovine neosporosis: a comparative study of commercially available ELISA tests. Vet Parasitol. 2013; 198: 85-95.

21. Djokich V, Klun I, Musella V, Rinaldi L, Cringoli G, Sotiraki S, et al. Spatial epidemiology of Toxoplasma gondii infection in goats in Serbia. Geospatial Health. 2014; 8: 479-488.

22. Liu Z K, Li J Y, Pan H. Seroprevalence and risk factors of Toxoplasma gondii and Neospora caninum infections in small ruminants in China. Prev Vet Med. 2014; 118: 488-492.

23. Gazzonis A L, Veronesi F, Di Cerbo A R, Zanzani S A, Molineri G, Moretta I, et al. Toxoplasma gondii in small ruminants in Northern Italy - prevalence and risk factors. Ann Agric Environ Med. 2015; 22: 62-68.

24. Hamilton C M, Katzer F, Innes E A, Kelly P J. Seroprevalence of Toxoplasma gondii in small ruminants from four Caribbean islands. Parasit Vectors. 2014; 7: 449.

25. Nasir A, Ahsraf M, Khan M S, Javeed A, Yaqub T, Avais M, et al. Prevalence of Neospora caninum antibodies in sheep and goats in Pakistan. J Parasitol. 2012; 98: 213-215.

26. Pérez-Creo A, Díaz P, López C, Béjar J P, Martínez-Sernández V, Panadero R, et al. Fasciola hepatica in goats from north-western Spain: Risk factor analysis using a capture ELISA. Vet J. 2016; 208: 104-105. 